\title{
Effect of scaffold pore size on cell behaviour in vitro
}

\section{Journal Article}

\section{Author(s):}

Schroeder, A.; Blum, J.; Mayer, J.; Karamuk, E.; Wintermantel, E.

Publication date:

1996

Permanent link:

https://doi.org/10.3929/ethz-b-000422539

Rights / license:

In Copyright - Non-Commercial Use Permitted

Originally published in:

Biomedizinische Technik 41(s1), https://doi.org/10.1515/bmte.1996.41.s1.436 


\title{
Effect of scaffold pore size on cell behaviour in vitro
}

\author{
Schroeder A., Blum J., Mayer J., Karamuk E., Wintermantel E. \\ Chair of Biocompatible Materials Science and Engineering, Department of Materials, \\ ETH Zürich, CH-8952 Schlieren, Switzerland
}

\begin{abstract}
INTRODUCTION:
The construction of artificial tissues requires that cell growth and differentiation on the scaffold biomaterial be controlled. Studies on foam-based implants suggest that scaffold pore size may affect the type and extent of cell ingrowth. However, the scaffolds used so far have suffered from a lack of well-defined and uniform pores. In addition, the effect of pore size in relation to the conditions under which three-dimesional cell-scaffold constructs are grown has been poorly documented. To investigate these parameters, we examined the behaviour of MC3T3-E1 cells on stainless steel wire netting, with defined mesh sizes, under static or dynamic culture conditions in vitro. MC3T3-E1 is an osteogenic cell line derived from mouse calvaria which is known to retain its cell-typical characteristics, such as mineralisation, in culture [1]. Cell proliferation, viability and distribution were determined qualitatively and quantitatively using specially adapted fluorescence techniques.
\end{abstract}

\section{MATERIALS AND METHODS:}

Stainless steel wire mesh scaffolds (Din 1.4401, G. Bopp, Switzerland), consisting of $1 \mathrm{~cm}^{2}$ squares with mesh sizes ranging from 50 to $500 \mu \mathrm{m}$, were sterilised by autoclaving at $120^{\circ} \mathrm{C}, 1$ bar for $50 \mathrm{~min}$ before use.

MC3T3-E1 cells (Dept. Pathophysiology, University Bern, Switzerland) were cultured in $\alpha$-MEM medium containing $5 \%$ fetal calf serum and $0.2 \%$ gentamycine (all from Gibco, Scotland) and incubated at $37^{\circ} \mathrm{C}, 5 \%$ $\mathrm{CO}_{2}$ and $95 \%$ relative humidity. After a week in culture, the growth medium was supplemented with $25 \mu \mathrm{M}$ ascorbic acid and $10 \mathrm{mM} \beta$-glycerolphosphate (both from Fluka, Switzerland) to enhance cell differentiation. For experiments, cells were harvested by trypsinisation and seeded, at a concentration of 150000 cells $/ \mathrm{ml}$ growth medium, onto the scaffolds.

Scaffolds were placed individually in wells of 24 well culture dishes (Nunc, Denmark) and seeded with $1 \mathrm{ml}$ cell suspension for studies under static conditions. For dynamic conditions, scaffolds were skewered onto a 200 $\mu \mathrm{m}$ steel wire, affixed to the rim of a $100 \mathrm{ml}$ glass bioreactor, seeded with $30 \mathrm{ml}$ cell suspension and cultivated under continuous stirring. Medium was changed every 3 days. All determinations were carried out in triplicate.

Cell viability and distribution on scaffolds were monitored qualitatively by light microscopy and by simultaneous fluorescent labeling of cells with calcein$\mathrm{AM}$ and ethidium homodimer (both from Molecular Probes, USA). Viable cells are stained green by the reaction of calcein-AM with intracellular esterases. Ethidium homodimer intercalates into the DNA of nonviable cells which stain red. Labeling was visualised on an inverted microscope equipped for fluorescence (Axiovert, Zeiss, Germany). Qualitative fluorescence techniques are especially appropriate to monitor cells on scaffolds which appear opaque to light microscopy.

Cell proliferation was quantified by a fluorometric DNA dye binding assay [2] adapted for our scaffolds, which do not respond to conventional cell harvesting methods, such as trypsinisation. Cells on scaffolds were lysed by two cycles of freeze-thawing in $400 \mu \mathrm{l}$ ultrapure water followed by the addition of $100 \mu \mathrm{l}$ of the fluorochrome bisbenzimide (Hoechst 33258, Sigma, USA) to $100 \mu \mathrm{l}$ cell lysate. The fluorescence (excitation $350 \mathrm{~nm}$; emission $460 \mathrm{~nm}$ ), measured in a fluorescence reader (Cytofluor, Molecular Dynamics, USA), is proportional to cell number.

\section{RESULTS:}

Qualitative calcein-AM fluorescence labelling clearly showed the growth and distribution of cells on the scaffold. After 2 days in static culture, cells on the $50 \mu \mathrm{m}$ mesh grew preferentially in the pores while those on the $500 \mu \mathrm{m}$ mesh occupied the scaffold frame and the periphery of the pores only (Figure 1). Vital cells on both mesh types far outnumbered dead cells (not illustrated), which demonstrated the non-toxic nature of the scaffold. After 14 days incubation, the pores of the $50 \mu \mathrm{m}$ meshes were completely spanned with cells. While the $500 \mu \mathrm{m}$
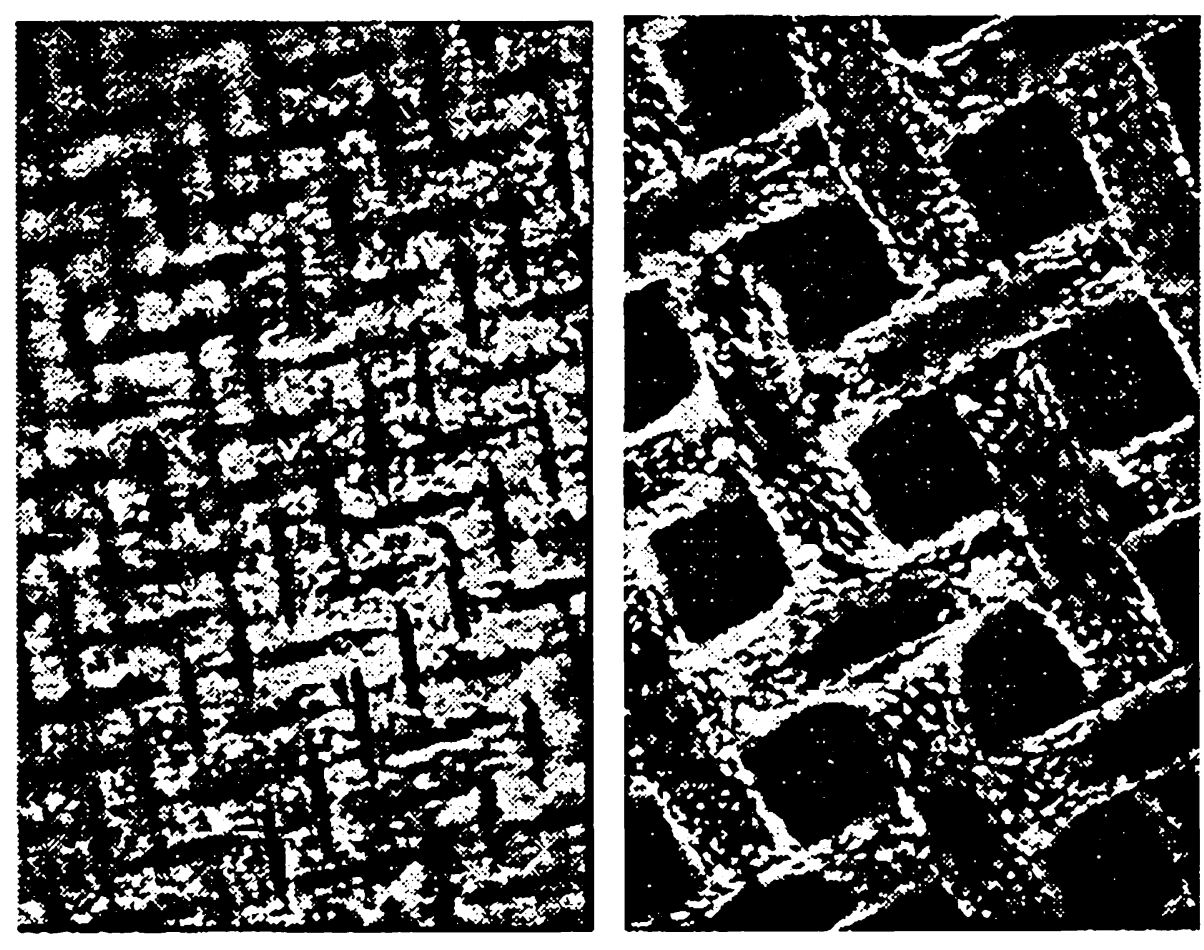

Figure 1: Proliferation patterns of MC3T3-E1 cells on stainless steel scaffolds after 2 days under static culture conditions. Light areas on the fluorescence images correspond to viable cells labelled with calcein-AM. Magnification $\times 1000$. Left: cells on $50 \mu \mathrm{m}$ mesh. Right: cells on $500 \mu \mathrm{m}$ mesh. 

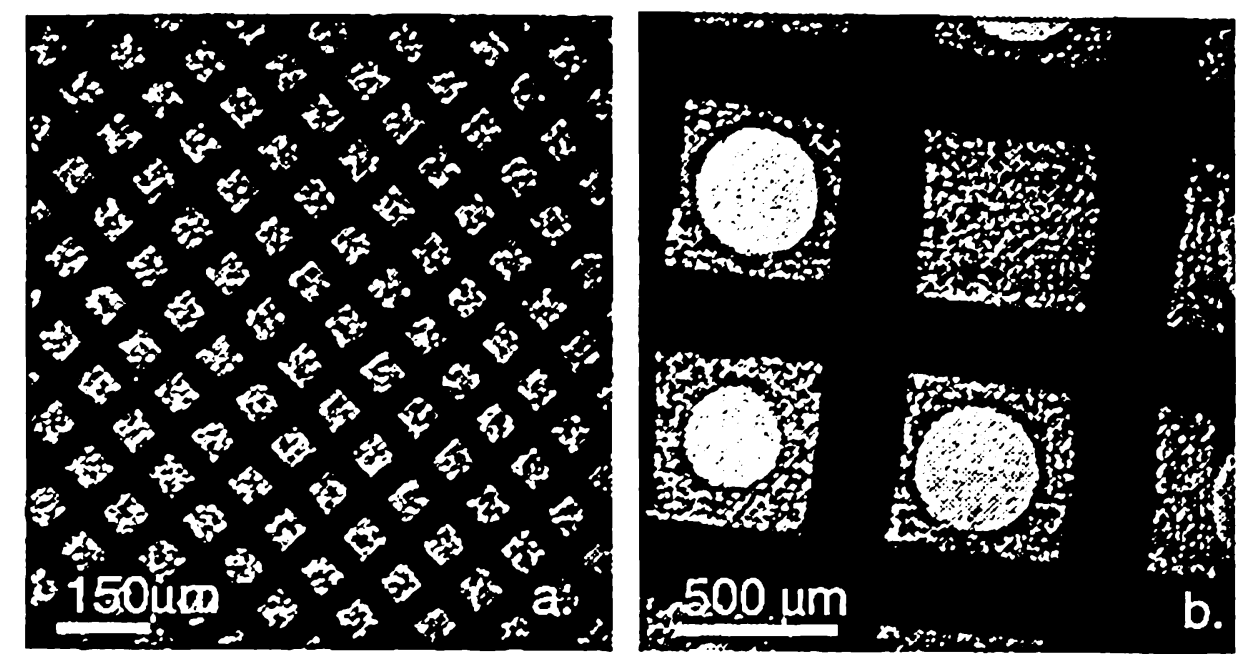

Figure 2: Light microscopic images (no staining) of the proliferation patterns of MC3T3-EI cells on stainless steel meshes after 14 days under static culture conditions .Magnification $\times 1000$ Left: cells on $50 \mu \mathrm{m}$ mesh. Right: cells on $500 \mu \mathrm{m}$ mesh

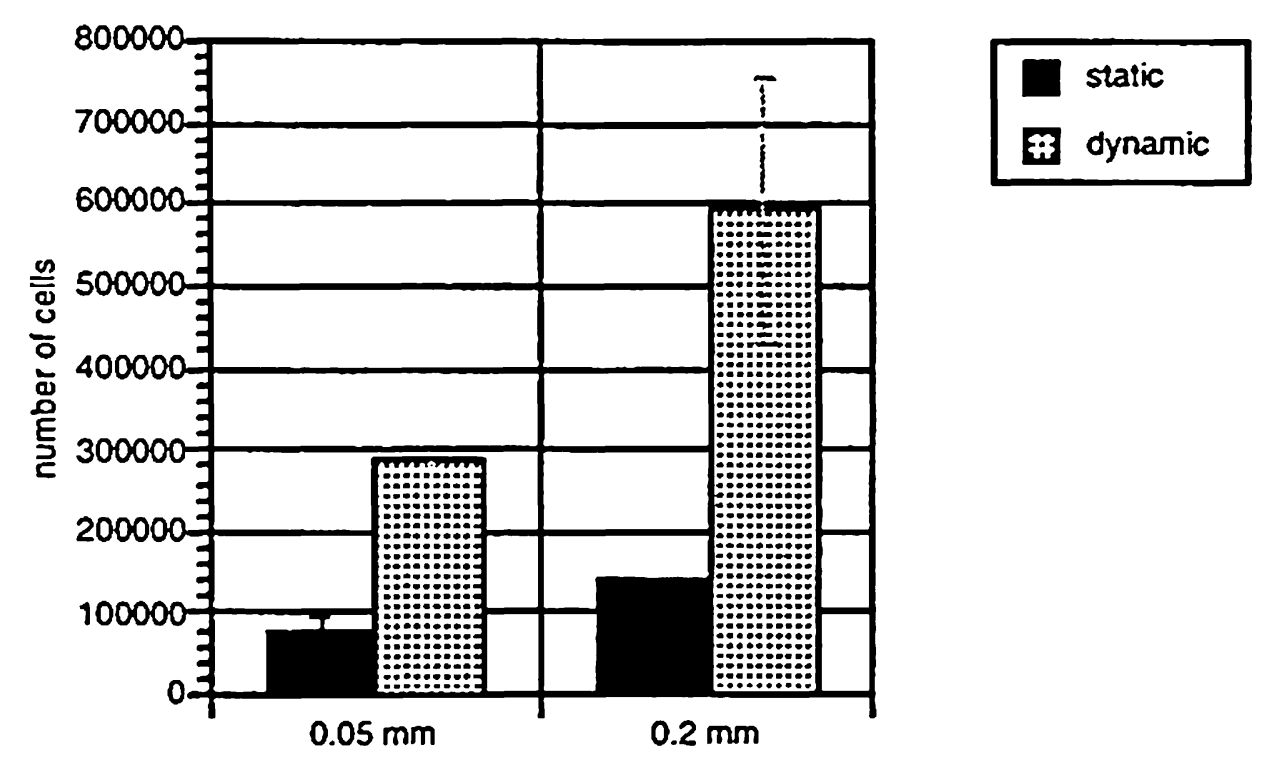

Figure 3: The effect of dynamic and static culture conditions on the proliferation of MC3T3-EI cells on stainless steel scaffolds with mesh sizes of 50 and 200 $\mu \mathrm{m}$ after 14 days. Quantitative assessment of cell number was performed by fluorescent dye-binding assay.

meshes were unevenly filled, it was observed that the cells always proliferated from the periphery of the pores to the centre in a concentric fashion (figure 2).

The significance of pore size on the proliferation of cells under differering culture conditions was then investigated quantitively using fluorescent marking of cell DNA. Under both static and dynamic conditions, scaffolds with larger mesh sizes consistently yielded higher cell numbers than those with small pores. However, the number of cells obtained with scaffolds of uniform mesh size was significantly higher under dynamic conditions in a bioreactor than in a multiwell dish (figure 3 ).

\section{DISCUSSION}

The evaluation methods employed in this report demonstrate the applicability of the MC3T3-E1/stainless steel mesh constructs as models for the study of artificial tissue systems. Qualititive fluorescence labeling also made possible the visualisation of initial cell attachment and growth to the scaffold with larger mesh size, a phenomenon that cannot be detected by light microscopy.

Preliminary results indicate an effect of pore size on cell proliferation and distribution on scaffolds. Large mesh sizes in the range of 200 to $500 \mu \mathrm{m}$ appear to be more suitable for cell growth than the smaller $50 \mu \mathrm{m}$ meshes under both culture conditions examined. However, the effect of the culture conditions seem to outweigh the benefits of increased pore size. Cells on small meshes under dynamic culture conditions proliferate better than those on large meshes under static conditions. Cell growth in bioreactors is enhanced due to the movement of the medium which leads to more efficient transport of nutrients to the cells and removal of waste products. In contrast, cell growth in static multiwell dish culture is limited by the rate of nutrient diffusion and waste accumulation.

These preparative experiments were performed to determine the most suitable pore size and culture conditions for efficient provision of nutrients for the growth of cells on scaffolds. In addition, the significance of these parameters on the differentiation of osteoblasts are currently being assessed in investigations using assays for alkaline phosphatase and mineralisation. These studies will be extended to multilayered scaffold constructs as a basis for creating artificial tissues.

\section{REFERENCES}

1. H. Kodama et al; Jpn J Oral Biol 23, 899-901 (1981)

2. R. Rago et al; Anal Biochem 191, 31-34 (1990) 